IJQRM

11,6

50

Received A pril 1992 Revised July 1993
International Journal of Quality \& Reliability Management, Vol. 11 No. 6, 1994, pp. 50-56 (c) M CB University Press, 0265-671X

\section{$\delta$ Charts for Short Run Statistical Process Control}

\author{
Victor E. Sower
}

Sam Houston State U niversity, Texas, USA, Jaideep G. Motwani

Grand Valley State University, M ichigan, USA, and

Michael J. Savoie

Integrated Resources Group, Louisiana, USA

\section{Introduction}

Many manufacturing organizations feel they cannot utilize statistical process control (SPC) charts because their average product run length is too short. Infrequent, short production runs do not lend themselves to the usual variable $\bar{X}$ and Range (R) control charts[1, p. 292]. Under certain conditions, a $\delta$, or differencefrom-nominal, control chart can provide a means for providing statistical control of a short-run process. The purpose of this article is to describethe $\delta$ control chart and the conditions appropriate for its use. Other types of difference control charts are compared with the $\delta$ chart and the appropriate application for each is discussed. A brief case analysis describes the use of the $\delta$ chart in a metal fabrication operation.

\section{Background}

Statistical control of a process by variables is accomplished through the use of a pair of control charts. One chart, usually an $\bar{X}$ chart, records between-subgroup variations in the process. The other chart, usually a Range (R) or Standard Deviation (S) chart, records within-subgroup variations in the process. The combined information from the two charts provides a means of monitoring and statistically controlling the process.

The control limits for $\bar{X}$ and $R$ charts are based on data taken from at least 20 to 25 samples of product from the process[2, p. 203]. This is quite feasible for long production runs, but often impossible for short production runs. In many cases the production run is over before sufficient data can be collected to establish the control limits for the process.

W here control limits for the process have al ready been established, short production runs will often produce only a few new points on the control charts. These few points may be insufficient to detect trends in the process. Control charts maintained for each product produced in a flexible manufacturing process end up being collections of disjoint information. Further, the information contained in the control chart for Product $A$ is not availablewhen Product $B$ is run using the same process. A single control chart which could display time series 
data for all products manufactured in that process would provide much more information about the performance of that process.

$\delta$ Charts for Short Run

\section{Difference Control Charts}

The $\delta$ chart, described in this article, is a type of difference control chart. Difference control charts plot the deviation of the data from some standard or other measurement rather than plotting the data directly. The term " $\delta$ chart" was applied to a specific type of difference control chart in 1991[3]. A $\delta$ chart, providing certain requirements are met, allows data from multiple products manufactured in the same process to be plotted on a single chart.

Grubbs[4] proposed a difference control chart for use in instances where systematic measurement variations exceed the variations in the quality being measured. Bicking et al.[5, pp. 29-44] describe another type of difference control chart system utilized for adaptive control in the chemical process industry. Bicking et al.'s difference charts are not true SPC control charts in that they do not provide a statistical basis for judging whether the process is in control.

M ore recently, the $\delta$ chart, with different names, has become more prominent. Montgomery [6, p. 314], discusses a control chart which plots the deviation from nominal instead of the measured variable on the control chart. This chart, which is referred to as the deviation from nominal chart by Montgomery, was not discussed in the first edition of M ontgomery's book. Bothe[7] discusses the use of a Nom-i-nal chart for short-runs of different products with approximately the same standard deviation on the same process equipment. Farnum[8] refers to a DNOM chart which charts deviations from nominal values. Pyzdek[9] discusses a code value chart which charts the deviation from target (nominal) divided by the unit of measure (to avoid having many zeros between the significant figure and the decimal point).

The $\delta$ control chart is a type of difference control chart which is the same as Montgomery's deviation from nominal, Bothe's Nom-i-nal, and Farnum's DNOM charts, similar to Pyzdek's code value chart, but different from both Grubbs' and Bicking et al.'s charts. It is especially applicable for short-run SPC situations. A brief comparison of difference control charts is shown in Table I.

\section{The $\delta$ Control Chart}

Difference control charts plot deviations from some reference rather than plotting the measured values directly. In the case of the delta control chart, the statistic which is plotted is the difference between the measured value of the statistic and the nominal value (or setpoint). This difference is called the $\delta$. The benefit of plotting the $\delta$ rather than the actual measurement is readily apparent when the process being monitored is used for short production runs of products where the nominal value varies. W hen the nominal value varies from run to run but the variances of the individual runs are the same (or nearly so) and the sample size is constant for all products, one $\delta$ control chart may be used to monitor the process for all of the individual runs.

The conditions under which a $\delta$ chart might be used are commonly encountered in many industrial processes. W hen processes are operated away 


\begin{tabular}{|c|c|c|c|}
\hline \multirow[t]{2}{*}{$\begin{array}{l}\text { IJQRM } \\
11,6\end{array}$} & Chart type & Characteristics & Application \\
\hline & Grubbs' difference chart & $\begin{array}{l}\text { Obtains and plots difference } \\
\text { between measurements of test } \\
\text { samples and a standard sample }\end{array}$ & $\begin{array}{l}\text { Excessive } \\
\text { environmental } \\
\text { variation }\end{array}$ \\
\hline \multirow[t]{3}{*}{52} & A daptive control charts & $\begin{array}{l}\text { Plots differences between } \\
\text { process set point and actual } \\
\text { readings of process parameters. } \\
\text { Specifies action to be taken } \\
\text { to recentre process }\end{array}$ & $\begin{array}{l}\text { A daptive } \\
\text { control } \\
\text { of chemical } \\
\text { processes }\end{array}$ \\
\hline & $\delta$ control chart ${ }^{a}$ & $\begin{array}{l}\text { Obtains and plots difference } \\
\text { between nominal value and } \\
\text { measured value of a parameter }\end{array}$ & $\begin{array}{l}\text { SPC for } \\
\text { short } \\
\text { production } \\
\text { runs where } \\
\text { variances } \\
\text { are equal }\end{array}$ \\
\hline & \multicolumn{3}{|l|}{$\delta$ control charts include: } \\
\hline $\begin{array}{l}\text { Table I. } \\
\text { Comparison of Three } \\
\text { Types of Difference } \\
\text { Control Charts }\end{array}$ & \multicolumn{2}{|c|}{$\begin{array}{l}\text { M ontgomery's deviation from nominal chart, } \\
\text { Bothe's Nom-i-nal chart, } \\
\text { Farnum's DNOM chart, } \\
\text { Pyzdek's Code Value chart, } \\
\text { as well as the del ta chart discussed in this article }\end{array}$} & \\
\hline
\end{tabular}

from the extremes (i.e. near the centre) of their design limits, it is not unusual to find that the variances around a variety of set-points are equal or nearly so. When processes are operated near the extremes of their design limits, sometimes other sources of variation occur which result in greater variation than for nominals nearer the midpoint of the operating limits. Figure 1 illustrates this situation. $\delta$ charts may be employed where the variances around the set-points are equal.

The calculated upper and lower control limits for control charts are sample size dependent. For this reason, the sample sizes used for each product must be constant in order to plot multiple products on a $\delta$ chart.

\section{Figure 1.}

Typical Increase in Process Variation Near Operating Limits

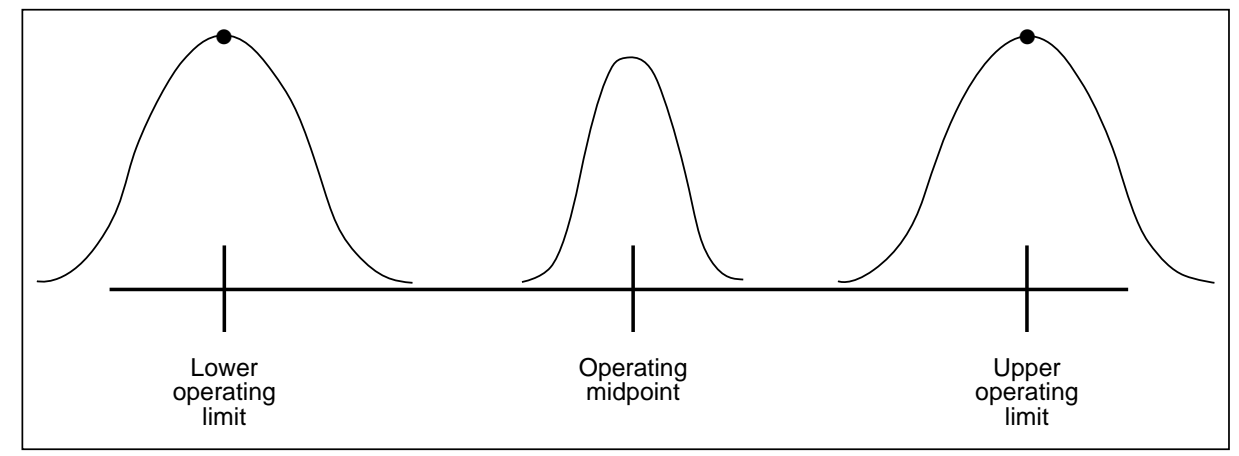


When production runs are short, it is difficult to monitor the variation about the process mean with a traditional $X$ variable control chart. Even with frequent sampling of the process output, a single run may comprise only a few points on the charts. The next run of the same product might be separated by a variety of other runs. This leads to a series of discontinuous observations of the process over time.

This situation sometimes leads management to abandon variable control charts in favour of some form of attribute control chart. While this is a valid approach, considerable information is lost when attribute control charts are substituted for variable control charts. The $\delta$ control chart overcomes this problem by providing a means of plotting the data from a variety of short production runs on the same chart. This provides a continuous record of the performance of the process and facilitates the identification of trends away from normal process operation.

One example of a process for which a $\delta$ chart might be suited would be a speciality bottle filling process. A process designed automatically to fill bottles between 1 ounce and 1 gallon might be used to produce 1 pint, 1 quart, and halfgallon sizes of the same product. The fill volumes are reasonably away from the design limits of the process. A relatively quick assessment could be made of the fill size variance for the three fill volumes. If the variances are equal, one delta chart could be used to monitor the process. The procedure would consist of plotting the sample mean difference $(\delta$ statistic) from the set-point fill volumes for samples taken from the process. The range value would be calculated and plotted in the normal way on a range chart.

Given equal population variances, the control limits for the $\delta$ chart would be calculated in the same way as for a normal X-bar chart. The centreline of the $\delta$ chart would be set at the grand average of the measured differences from the nominal value ( $\delta$ statistics). For a properly centred process, the centreline would be 0 .

$$
\begin{aligned}
\overline{\mathrm{x}}=\delta \text { statistic }= & \frac{\left.\mathrm{x}_{1}-\mathrm{NOM}\right)+\left(\mathrm{x}_{2}-\mathrm{NOM}+\ldots+\left(\mathrm{x}_{\mathrm{n}}-\mathrm{NOM}\right)\right.}{\mathrm{n}} \\
\mathrm{UCL} & =\text { grand average } \delta \text { statistic }+\mathrm{A}_{2} \overline{\mathrm{R}} \\
\overline{\overline{\mathrm{x}}}=\mathrm{CL} & =\text { grand average of the } \delta \text { statistics }(\overline{\mathrm{x}}) \\
\mathrm{LCL} & =\text { grand average } \delta \text { statistic }-\mathrm{A}_{2} \overline{\mathrm{R}} .
\end{aligned}
$$

The values for the associated $R$ chart would be calculated in the usual way. The standard rules for judging whether the process was in control would apply[10].

\section{$\delta$ Charts in Metals Fabrication: A Case A nalysis}

The metal fabrication division of a major corporation began training its employees in the techniques of statistical process control (SPC) during the summer of 1988. The first application for SPC was a process which used metal cutting saws and punch presses to produce the upper and lower housings for a 
IJQRM

11,6

54

variety of different sized electrical power outlet strips. The main customer for these housings had complained of mismatches in the lengths of upper and lower housings even though both were within allowed tolerances. They had also rejected several shipments based on an acceptance sampling procedure which revealed the lots contained an excessive number of parts whose lengths were outof-tolerance.

The metal cutting saws were used to cut a variety of different length top and bottom housing sections for the power strips. The length of these housing sections varied from 6 to 14 inches. All lengths used the same basic extruded aluminium raw material strips. To change from one length to another, the operator adjusted a hard stop on the saw table. Coarse adjustment was accomplished by positioning a stop and securing it with a set-screw. Fine adjustment was accomplished by inserting shims as required. The tolerance limits around each set-point were the same, \pm 0.020 inches. Since the top and bottom housings were cut separately, it was highly desirable to avoid the extremes of the tolerance limits since it was possible to have a tolerance build-up resulting in as much as a 0.040 inch mismatch between the length of the top and bottom housings.

The plant initially tried to use $\bar{X}$ and range charts to control the process. The small run sizes created a problem. The duration of a typical production run was about oneshift (eight hours) or less. Sampling the process every half hour resulted in no more than 16 samples per run. When a different product run began, the operator had to start a new chart. None of the information contained in the previous charts was used in deciding whether the process was still in control at the start of the subsequent run.

Since at least 25 sample statistics were required to establish control limits, extra sampling was required during process capability studies. The plant considered abandoning the SPC system because SPC required so much more testing than the previously used acceptance sampling procedures. B efore abandoning SPC, they agreed to try the $\delta$ chart system.

The first step in using a $\delta$ chart for this process was to verify that the variances in the lengths of the various size housings were equal. This was accomplished by measuring 100 units of each length housing and calculating the variance. The variances were found to be equivalent to within 0.0015 square inches. A $n \mathrm{~F}$-test indicated that this difference was not significant.

A process capability study was conducted using $\delta$ and R charts. A ssignable causes that were detected were addressed. Figure 2 is a composite $\delta$ chart with a compressed time scale which covers the entire study period. The actual time period represented by this chart is about 45 days. The control limits are the trial control limits which resulted from the capability study.

The first ten points represent monitoring the process as designed. T he first two out-of-control points (points A and B) in Figure 2 were the result of improper setup. This was addressed by standardizing and documenting the set-up procedure and training all operators in that procedure. The third out-of-control point (point C) resulted from the stop slipping after set-up. This was corrected by redesigning theset-screw holding device. The third out-of-control point (point D) resulted from 


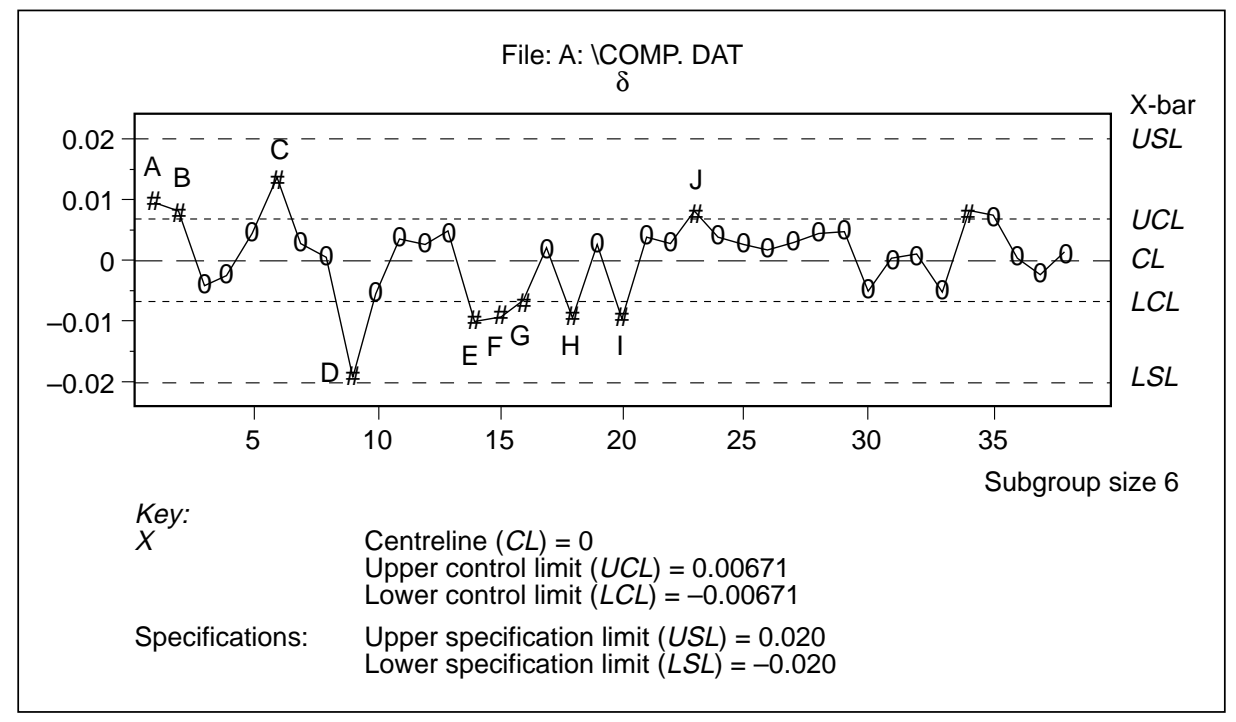

$\delta$ Charts for Short Run Process Control

55

a chip build-up ahead of the stop. This was corrected by installing a vacuum system to remove the chips after cutting. During this time the operators received training in interpreting control chart signals and in problem-solving techniques.

Statistics were then collected for 25 samples while the process was closely monitored to assure that it was behaving normally (from an engineering perspective). These statistics were used to calculate the trial control limits for the $\delta$ and R charts, and to calculate the process capability ratio $\left(C_{p k}\right)$.

The resulting $\delta$ and $\mathrm{R}$ charts were used to monitor and control the process for all the lengths processed. The remaining 28 points in Figure 2 show a typical chart which represents data from samples of products of three different lengths. Out-of control points E-I were the result of a single operator failing to follow the proper procedure for feeding the extrusions to the saw. All of the operators working as a team determined the cause and implemented the necessary corrective action. Point J resulted from a set-up problem - an additional shim was required to bring the process into control. The operators intentionally set the process slightly to the high side of nominal on the premiss that an oversized housing could be reworked while an undersized housing must be scrapped. This tendency to "safe-side" the set-up should disappear after sufficient confidence in the SPC process is gained.

The charts were maintained by the operator at themetal saw. T his provided the operator with immediate feedback on the validity of the initial set-up of the saw and on whether the process was operating in statistical control. The last 28 points in Figure 2 show that this process was not yet in full statistical control. However, unlike the pre-SPC situation, none of the excursions were outside the tolerance limits. By investigating the causes for the out-of-control points, the $\delta$ and $R$ charts can be used as tools for the continuing improvement of the process. 
IJQRM 11,6

The continuing improvement process will result in the identification and elimination of assignable cause variation and the minimizing of the random variation of the process.

If indeed a process capability study could result in the total and eternal elimination of all possible assignable cause variations, continuous monitoring with control charts would be unnecessary. In reality some assignable causes reoccur, or new assignable causes are introduced. The beauty of the control chart is the quick identification of an out-of-control condition which allows rapid corrective action to take place.

The $\delta$ chart system allow ed the operators adequately to control the process by taking samples at approximately hourly intervals. This was half the sampling rate of theX chart system tried previously. Implementation of the $\delta$ chart system resulted in a continuance of the SPC system rather than a reversion to acceptance sampling. The result was a complete elimination of rejected housings at subsequent operations due to out-of-tolerance lengths.

\section{Conclusions}

Short-run processes represent a challenge for traditional SPC control charting techniques. The $\delta$ chart has been_shown to be an effective technique for addressing the limitations of $\bar{X}$ charts for short production runs. In conjunction with standard range charts, $\delta$ charts can provide an effective means to monitor and control processes which might otherwise be deemed unsuitable for SPC control charting.

\section{References}

1. Hayes, G.E., Quality A ssurance: M anagement and Technology, Charger Productions, Capistrano Beach, CA, 1974.

2. Montgomery, D.C., Introduction to Statistical Quality Control, 2nd ed., John Wiley $\&$ Sons, New York, NY, 1991.

3. Sower, V.E., M otwani, J.G., and Savoie, M.J., "T he Use of Delta Charts in Short Run Statistical Process Control", 1991 A SQC Quality Congress Transactions, 1991, pp. 528-32.

4. Grubbs, F.E., "T he Difference Control Chart with an Example of Its Use", Industrial Quality Control, July 1946, pp. 22-5.

5. Bicking, C.A., Hinchen, J.D. and R.S. Bingham, R.S., "Chemical Process Industries", in Juran, J.M., Gryna, F.M. and Bingham, R.S. (E ds), Quality Control Handbook. McGraw-Hill, New York, NY, 1974.

6. Montgomery, D.C., Introduction to Statistical Quality Control, 1st ed., John W iley $\&$ Sons, New York, NY, 1985.

7. Bothe, D.R. "SPC for Short Production Runs", Quality, December 1988, pp. 58-9.

8. Farnum, N.R., "Control Charts for Short Runs: Nonconstant Process and Measurement Error", Journal of Quality Technology, July 1992, pp. 138-44.

9. Pyzdek, T., "Process Control for Short and Small Runs", Quality Progress, A pril 1993, pp. 51-60.

10. Western Electric, Statistical Quality Control Handbook, Western Electric Corporation, Indianapolis, IN, 1956. Indianapolis, 1956. 